\title{
Research of experimental hybrid energy complex with fuel cells operating on biogas
}

\author{
A. B. Loskutov ${ }^{1, *}$, E. N. Sosnina ${ }^{1}$, A. I. Chivenkov ${ }^{1}$, E. V. Kryukov ${ }^{1}$, and A. P. Shashkin ${ }^{1}$ \\ ${ }^{1}$ Nizhny Novgorod State Technical University n.a. R.E. Alekseev, Nizhny Novgorod, Russia
}

\begin{abstract}
The article deals with the development of a hybrid energy complex (HEC) based on solid oxide fuel cells (SOFC) operating on biogas. Low maneuverability of SOFC prevents a widespread use of such power installations in consumers' power supply systems. The authors have developed the design of the HEC and an active-adaptive control system that allows solving the problem of SOFC low maneuverability. An experimental HEC consisting of a SOFC generation system, an accumulation system, a coupling system and a control system have been created. The research of the experimental HEC characteristics and the possibility of developing emergency situations during its operation has been carried out. The results of the charge and discharge characteristics of the accumulation system research, as well as the current and voltage dependences of the HEC coupling system are presented. The conducted studies have proved the effectiveness of the developed scientific and technical innovations.
\end{abstract}

\section{Introduction}

Recently much attention has been paid to the technologies of using biogas as a renewable and stable source of energy $[1,2]$. The main advantages of biogas are the availability of raw materials and the lack of fuel costs [3-5]. Also the use of biogas due to the utilization of biological waste can significantly reduce the environmental influence. According to the estimates of the world scientific community, the most promising and economically profitable way to convert biogas to energy is the use of solid oxide fuel cells (SOFC). The main advantage of SOFC in comparison with gas turbine and gas-piston units is a direct conversion of biogas to electricity due to the chemical reactions of combustible substances with oxidants in the cells. It enables to achieve higher efficiency and ensure the environmental cleanliness of the electricity generation process (there are no emissions into the atmosphere).

At present a number of large companies are engaged in the production of SOFC power installations: American companies "Bloom Energy", "Siemens Westinghouse", "General Electric", "Cummins", "Delphi Battelle", "Acumentrics", "Fuel Cell Energy", "Horizon Fuel Cell Technologies", German companies "Sunfire", "Stahera"; Chinese company "Sofcman" and other. The output power of installations is from 0.25 to $265.2 \mathrm{~kW}$.

A number of energy supply projects using SOFC, working on biogas may be noted. "Microsoft" used fuel cells operating on biogas from municipal wastewater treatment products to power a $200 \mathrm{~kW}$ data center in Wyoming. ENCE GmbH offers technical solutions for the use of fuel cells working on anaerobic gases for oil and gas companies energy supply.

However, despite the active development of SOFC technologies their widespread use in consumers' power supply systems is not sufficient $[6,7]$. The reason for this is a low maneuverability of the power plant and, as a consequence, its inefficient operation [8].

The problem of the low maneuverability of SOFC is solved by a hybrid energy complex (HEC) based on SOFC and an accumulation system developed by the authors. Experimental HEC has been created in Nizhny Novgorod State Technical University n.a. R.E. Alekseev [9]. The novelty of the proposed solution is the possibility of changing the power installation operating modes with the constant generated power of the SOFC electrochemical generator and the load power dynamic change, which has not been considered earlier. The developed HEC has increased the maneuverability, reduced the fuel consumption and increased the life of SOFC [10].

The article presents the main scientific and technical solutions for the hybrid energy complex with the SOFC development and the results of the experimental HEC research.

\section{Measurement of characteristics and analysis of partial discharges parameters}

The developed HEC with SOFC consists of a generating system, a power storage system, a coupling and an active-adaptive control system a. The structural diagram of the HEC is shown in Figure 1.

\footnotetext{
*Corresponding author: loskutov@nntu.ru
} 


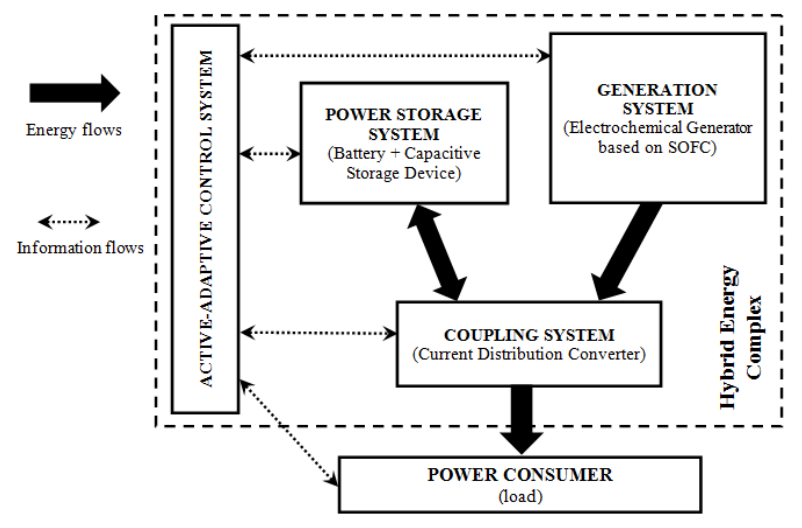

Fig. 1. Structural diagram of the hybrid energy complex.

The generation system with an electrochemical generator (ECG) based on SOFC provides a continuous operation of HEC for the basic part of the consumers' electrical load schedule. ECG has a modular execution. High-temperature parts are combined in one block: a SOFC stack, a reformer, an afterburning-heating system. The SOFC stack consists of planar elements [11].

The use of capacitive storage and nickel-cadmium batteries with the tubular-plate electrodes in the power storage system makes it possible to significantly improve the maneuverability of the power plant on SOFC. When the load falls below the set value, the accumulation of electricity occurs in the batteries. In case of the load excess, the battery provides the stored electrical energy into the network. The capacitive storage is used for a peak load supply.

NNSTU researchers have developed a technology of nickel-cadmium batteries with the tubular-plate electrodes manufacturing, characterized by cheapness and environmental friendliness. The specific cost of such accumulators is 1.5-2 times lower than the analogues with the same energetic characteristics able to work in a wide range of charge and discharge current densities and temperatures. The producing technology of a positive electrode doesn't include chemical metallization; the negative electrode is made by pressing and doesn't contain metalized foundation. Such technologies aren't used nowadays.

The coupling system provides generating and power storage systems connection and HEC currents redistribution [12]. The HEC coupling system is based on a current distribution converter (CDC) between its elements. CDC includes three DC/DC upconverters.

The active-adaptive control system performs monitoring of the HEC and load electrical parameters, regulating and controlling current distribution between the HEC elements and load depending on consumers' power. The control system works according to the algorithm shown in Figure 2.

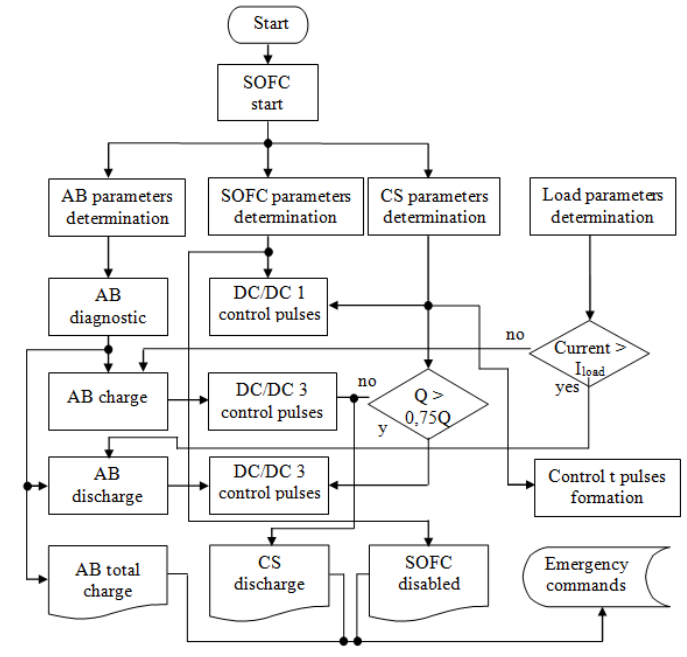

Fig. 2. An algorithm of the HEC with SOFC and power storage system operation.

The basic criterion of the algorithm is to maintain the voltage on the capacitors in a predetermined range (minimum $-350 \mathrm{~V}$, maximum $-450 \mathrm{~V}$ ). The minimum level of voltage matches the ability to ensure the efficiency of the DC/AC inverter - stabilization of the output AC voltage of $220 \mathrm{~V}, 50 \mathrm{~Hz}$, and the implementation of consumers' power supply in the power range from 0 to a nominal value.

In case of the constant power generation and load, the regulation of the current $\mathrm{AB}$ values and capacitors is carried out at the expense of the three structural elements: DC/DC converter 1, DC/DC converter 3 and $\mathrm{AB}$ state diagnostic unit

\section{Experimental Hybrid Energy Complex with SOFC}

The experimental HEC photo is shown in Figure 3. The maximum experimental HEC output power is $1.5 \mathrm{kVA}$, the output voltage $-220 \mathrm{~V}, 50 \mathrm{~Hz}$ [13].

The following experimental HEC research has been conducted: ECG electrical characteristics; battery charge and discharge characteristics; current distribution converter electrical characteristics.

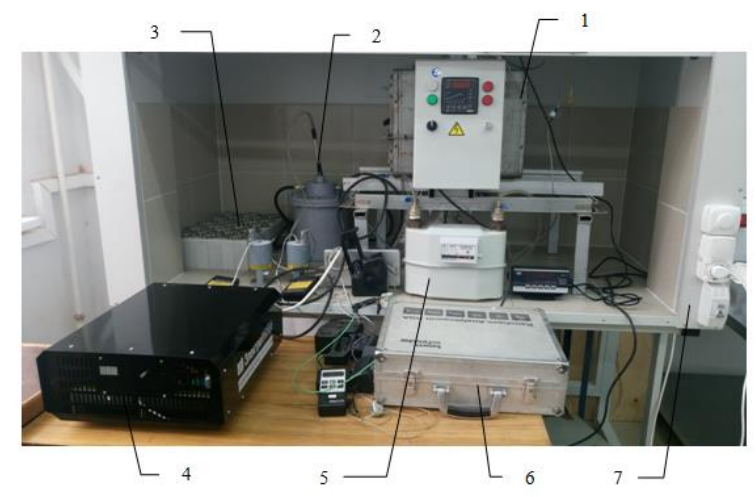

Fig. 3. Experimental HEC with SOFC: 1 - thermobox with SOFC stack; 2 - matrix converter; 3 - NCA battery; 4 - current distribution converter; 5 - gas flow meter; 6 - gas analyzer; 7 fume hood. 


\section{Results and discussion}

\subsection{Generation system research}

The ECG electrical characteristics were studied with the fuel consumption of $4 \mathrm{l} / \mathrm{min}$ and the air consumption of $15 \mathrm{l} / \mathrm{min}$. The research results are presented in table 1 . Figures 4-5 shows the experimental current-voltage and watt-ampere characteristics of ECG based on SOFC.

Table 1. The results of ECG based on SOFC research (4 1/min fuel consumption and $15 \mathrm{l} / \mathrm{min}$ air consumption).

\begin{tabular}{|c|c|c|c|}
\hline $\begin{array}{c}\text { Output } \\
\text { power, } \mathrm{W}\end{array}$ & $\begin{array}{c}\text { Output } \\
\text { voltage, } \mathrm{V}\end{array}$ & $\begin{array}{c}\text { Output } \\
\text { current, } \mathrm{A}\end{array}$ & Temperature, ${ }^{\circ} \mathrm{C}$ \\
\hline 86 & 26.0 & 3.31 & 750 \\
\hline 185 & 24.5 & 7.55 & 748 \\
\hline 340 & 20.2 & 16.83 & 749 \\
\hline 514 & 16.0 & 32.13 & 748 \\
\hline
\end{tabular}

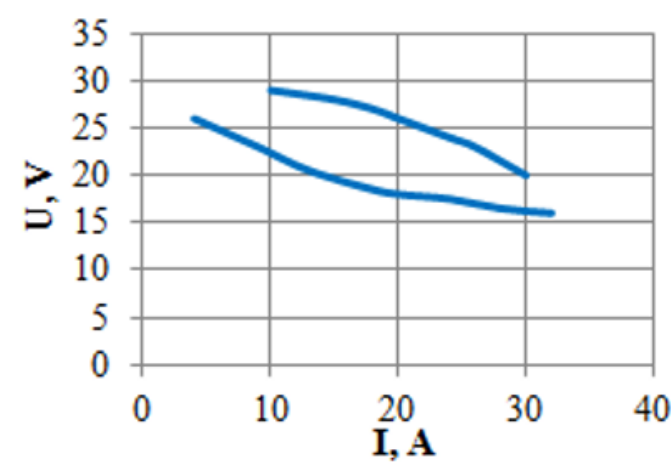

Fig. 4. Experimental current-voltage characteristics of ECG on SOFC: 1,2 - after carrying out experiments cycles, 3, 4initial characteristics.

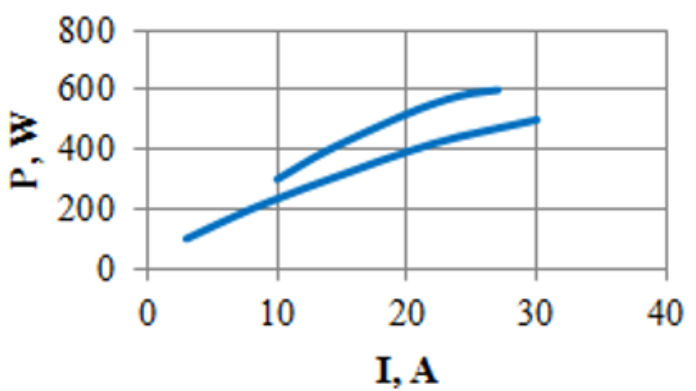

Fig. 5. Experimental watt-ampere characteristics of ECG on SOFC: 1,2 - after carrying out experiments cycles, 3, 4 initial characteristics.

The research results have shown that during a longterm operation of the ECG, a decrease in the output power and voltage was observed. However, it is insignificant and does not affect the efficiency of the HEC and the consumer.

As a part of the study, an assessment of the possible evolution of emergency situations during the installation operation has been made. The theoretical analysis and the results of practical tests have shown that the most dangerous points were the start and the stop of the installation. Uneven heating and stack destruction are possible in the process of starting in case of exceeding the heating rate. A similar situation is possible when cooling.

\subsection{Power storage system research}

Battery charge and discharge characteristics during the experiment were studied.

The time dependencies of current and voltage were obtained at different charge and discharge modes. The results are shown in Figures 6-9.

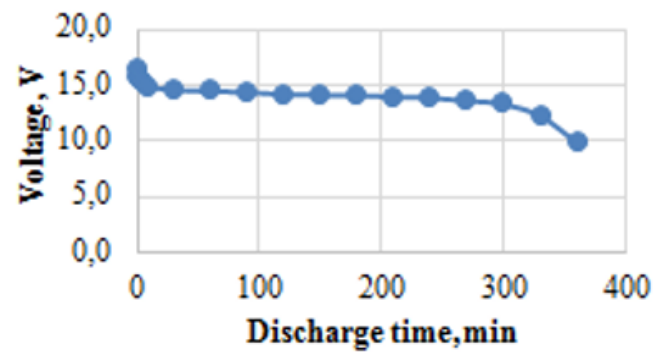

Fig. 6. Battery discharge voltage changing with discharge current $2.5 \mathrm{~A}$.

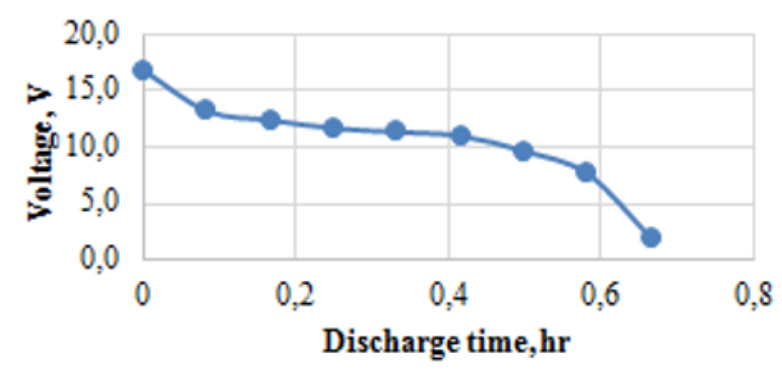

Fig. 7. Battery discharge voltage changing with discharge current $20.0 \mathrm{~A}$.

The results analysis has shown that the discharge time is about 6 hours with current 2.5 A (Figure 6). Battery voltage is stable for about 5.5 hours and there is a rapid decline in the last half hour. The battery average discharge voltage is $14.0-14.5 \mathrm{~V}$. The increase of the discharge current reduces the discharge time to 8 times. The dynamics of the operating voltage during $\mathrm{AB}$ discharge with the discharge current $20 \mathrm{~A}$ is shown in Fig. 7. To provide battery high discharge characteristics, its charge can be carried out in two ways: either by a constant current or by a constant voltage.

The charge at a 2.5 A constant current was carried out to $120 \%$ of rated capacity. Battery charging curve can be divided into two sections (Figure 8). Initially, it results in the formation of higher oxides of nickel in the positive electrode and the metal cadmium in the negative when the battery voltage is $16.5-18.0 \mathrm{~V}$. A further significant increase of voltage is due to the occurrence of oxygen liberation side reactions of nickel oxide electrode and hydrogen on the cadmium electrode. The final discharge battery voltage is up to $22 \mathrm{~V}$ at the chosen charge mode. Charge time is $8-10$ hours.

The charge of battery can be accelerated by applying a constant voltage mode. The charge is carried out with voltage $19.5 \mathrm{~V}$. At the initial period of the charge the 
Table 2. The results of the power flows redistribution between HEC nodes research.

\begin{tabular}{|l|c|c|c|c|}
\hline \multicolumn{1}{|c|}{ Mode } & No load & Nominal load & 2-fold load & 3-fold load \\
\hline Load current, A & - & 2.27 & 4.50 & 6.80 \\
\hline DC/AC current, A & 0.08 & 1.31 & 2.60 & 3.95 \\
\hline DC/DC1 current, A & 6.00 & 10.50 & 10.40 & 10.50 \\
\hline DC/DC2 current, A & 4.00 & - & - & - \\
\hline DC/DC3 current, A & - & - & 6.94 & 6.95 \\
\hline Spark gap current, A & 0.74 & - & - & - \\
\hline Capacitive storage current, A & 0.80 & 1.32 & 2.65 & 2.66 \\
\hline
\end{tabular}

current can reach the values of 13-15 A (Figure 9). Then a rapid reduction occurs. After 1.5 hours there is some stabilization of the current, but after 3 hours the amount of current is reduced again and it is stabilized at the level of 0.2 - 0.3 A. Charge time is $4-5$ hours.

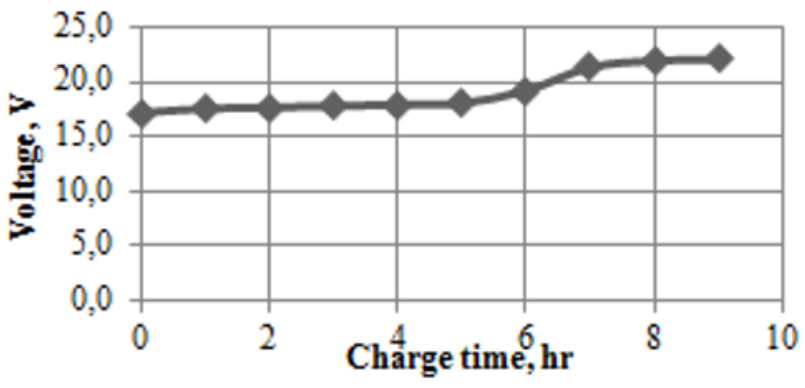

Fig. 8. Battery charge voltage changing with charge current 2.5 A.

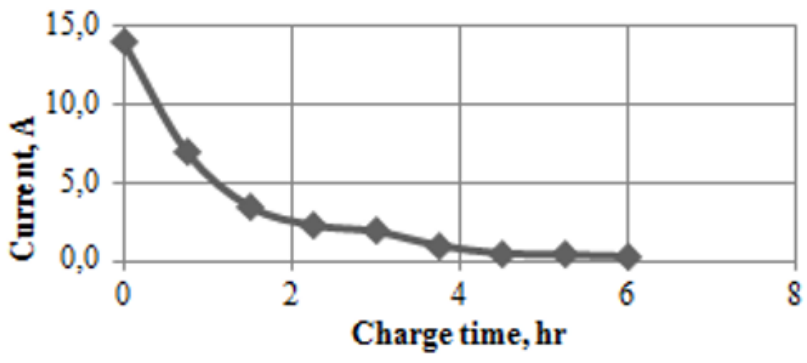

Fig. 9. Battery charge current changing with charge voltage $19.5 \mathrm{~V}$.

The results analysis has shown that DC source output power should not be less than $50 \mathrm{~W}$ when charging by the constant current. A battery charge by the constant voltage requires the use of semiconductor devices with an output power of up to $300-500 \mathrm{~W}$.

\subsection{Coupling system research}

The research of converters and a spark gap characteristics in the coupling system of the experimental HEC and the capacitive storage current at different values of the active load have been investigated. The results of the power flows redistribution between HEC nodes research are presented in table 2. The oscillograms of the output voltage at idling and under load are shown in Figures 10-11.

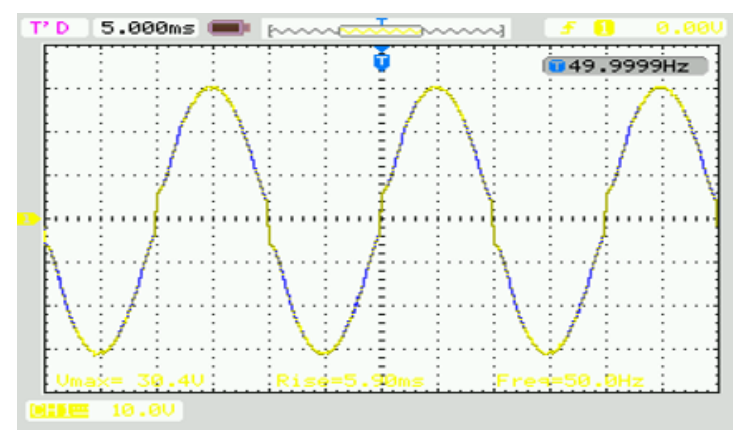

Fig. 10. The oscillogram of the output voltage at idling load.

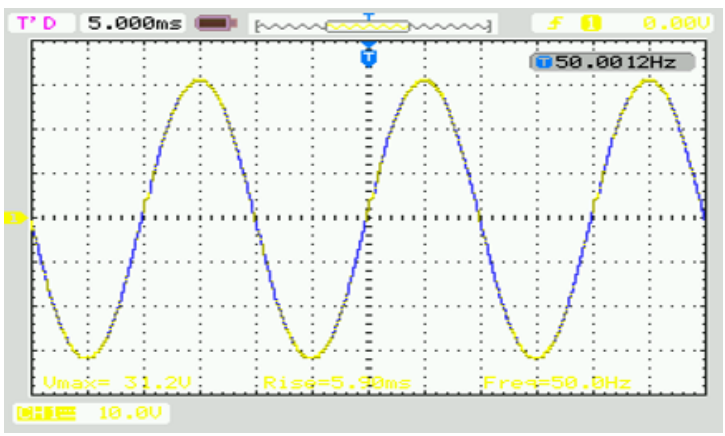

Fig. 11. The oscillogram of the output voltage at under load.

\section{Conclusion}

The conducted research of the experimental hybrid energy complex has proved the effectiveness and efficiency of the developed scientific and technical solutions. The decisions enable to provide electric power to the consumer with an electric load changing schedule with constant generated power of SOFC. This mode of operation increases the duration of the SOFC operation by 1.5 times with the maximum utilization factor (energy consumption per unit of generated capacity).

It is promising to use HEC for power supply systems of agricultural enterprises that can produce biogas from biowaste.

The work has been carried out with the financial support of the Ministry of Science and Higher Education of the Russian Federation (state task №13.2078.2017/4.6 on May 31, 2017). 


\section{References}

[1] N.V. Korovin, Fuel cells and electrochemical power plants (Moscow: Power Engineering Institute publishing house) 280 (2005)

[2] N. Laosiripojanaa, W. Wiyaratnb, W. Kiatkittipongc, A. Arpornwichanopd, A. Soottitantawatd, and S. Assabumrungratd, Engineering Journal 13(1), 65-83 (2009)

[3] SOFC tests and demonstrations: summary. Siemens $A G$. [Online]. Available: http://www.powergeneration.siemens.com/productssolutions-services/products-package/ fuelcells/demonstrations/demonstrations-summary

[4] Cummins Power Generation. 10kWe SOFC Power System Commercialization Program. [Online]. Available:

https://www.netl.doe.gov/File\%20Library/Events/2003/s eca/Daniel Norrick.pdf

[5] GE Fuel Cells. [Online]. Available: http://www.hydrogen.energy.gov/pdfs/htac_nov14_5 wellington.pdf

[6] S.I. Somov, Proc. Solid oxide fuel cells and power installations based on them Conf. (2010)

[7] I.V. Kiselev, Energy efficiency improving of solid oxide fuel cells and study their application to low power consumers energy supply (Russian federal nuclear center all-russian research institute of experimental physics) (2013)

[8] S. Jain, J. Jiang, X. Huang, and S. Stevandic, IEEE Trans.Industry Applications 48(4), 1142-1153 (2012)

[9] A.B. Loskutov, E.N. Sosnina, The development of scientific and technical solutions to build hybrid power source based on SOFC and storage system for responsible consumers (Nizhny Novgorod State Technical University, Nizhny Novgorod) (2016)

[10] A. Izadian, P. Famouri, Proc. American Science and Technology Conference (2007)

[11] A. Lipilin, and V. Lipilina, Modified planar cell and stack of electrochemical devices based thereon, and method for producing the planar cell and the stack, and a mould for producing the planar cell WO Patent 2013093607, (2013)

[12] A.I. Chivenkov, V.I. Grebenshchikov, A.P. Antropov, and E.A. Mikhailichenko, Engineering Herald of Don 24(1), (2013)

[13] A.B. Loskutov, E.N. Sosnina, A.I. Chivenkov, and E.V. Kryukov, IEEE Innovative Smart Grid Technologies - Asia (ISGT ASIA) Conf. (2015) 